\title{
APPLICATION OF INDUSTRIAL AUTOMATICS \\ sciendo SYSTEMS FOR MONITORING OF OPERATIONAL STATES OF MACHINES
}

doi:10.2478/mape-2018-0040

Date of submission of the article to the Editor: 04/2018 Date of acceptance of the article by the Editor: 07/2018

\author{
MAPE 2018, volume 1, issue 1, pp. 315-321
}

\section{Dr hab. inż. Jarosław Brodny}

Silesian University of Technology, Poland

\begin{abstract}
In the recent years, industrial automatics practically was used in all domains of economy. Particularly, it concerns to manufacturing processes and technological processes. It seems that in these systems, very important meaning have measuring and control devices, installed practically in all production machines. Operational parameters of machines, registered by these systems are the kind of source of very important information, which not always are utilized in proper way by the users. Particularly, it concerns mining branch, where more technically advanced machines are used. However, not always their users utilize the big potential of these machines. For this reason, in the paper there are presented results of studies, enabling the application of industrial automatic systems to analyze operation states of machines, based on registered parameters of these machines. Longwall shearer was submitted to detailed analysis as the most important machine in mining exploitation process. There are presented proposals for application registered data for determine effectiveness of its utilization and to diagnose its technical condition. Presented paper is aimed to realize and encouraging users to wider practical use of the capabilities of industrial automation systems. This should improve efficiency and safety of production processes.
\end{abstract}

Keywords: production process, industrial automatics systems, longwall shearer, efficiency, machine diagnostics.

\section{INTRODUCTION}

In the mining industry, similarly as in many other branches, more and more importance and application have industrial automation systems (Feng et al., 2008; Kwiecień, 2012). This process results from the development of informatics, automation, mechatronics and telecommunication (Bolton, 2007; Miu, 1993; Uhl, 2008). Also, more demanding and competitive market of goods and services forces actions in order to optimize the production costs. This in turn, causes that companies must increasingly use and apply modern technical solutions, which can provide them existence and development. Industrial automation systems include number of technical devices, which task is to automate production processes, monitoring and control of machines' operational parameters and realized processes, control of these machines and processes, as well as to ensure the proper communication.

From the efficiency of production process point of view, particular meaning have all kinds of sensors, detecting elements, indicators, meters and relays, which are used to diagnose operational parameters of particular devices and the entire technical systems (Hedman et al., 2016; Singh et al., 2018). As already mentioned, currently these systems are increasingly used in all fields where production processes are carried out. It results, that very modern and reliable machines, equipped in industrial automation systems, that effectively replace older solutions, are more available in the market.

Very significant meaning during implementation of this type of solution has also way of data application, which these systems register (Jonsson and Lesshamar, 1999). Currently, it seems that the largest reserves occur in this area. Paradoxically, many machine's users are unaware 
of the possibility of their industrial automation systems. However, application of these data is favored by increasing rate of changes related to the introduction of the fourth industrial revolution. This development is related to the society's striving to achieve maximum benefits at the least amount of work. This need is followed by engineering thought, which task is to create increasingly better and more efficient technical solutions. Proceeding changes are also visible in mining industry, which belongs to more conservative areas of economy. However, in the recent years, one can observe dynamic changes in the mining, which are mainly the consequence of high competition on the energy market. They also result from the wider utilization of alternative energy sources and strong emphasis on the environmental protection (Tutak and Brodny, 2017c; Tutak, 2017).

Very significant factor, which has large impact on the all optimization activities in mining has also specific environment, in which production activities are carried out. This applies mainly to various types of threats occurring in this environment, and having a significant impact on the course of this process (Brodny and Tutak, 2016a; Tutak and Brodny, 2017a; Tutak and Brodny, 2017b). All these phenomena cause that this industry also introduces changes in order to reduce unit costs and thus, to improve the efficiency of the entire production process. Element, which is very important in this process, is the appropriate awareness of employees and management staff. Great importance in this area have training courses of appropriate level for these people (Palka et al., 2017; Palka, 2017).

Therefore, in hard coal mining it is possible to observe the wider application of systems for monitoring of operation of machines and devices. Very significant meaning in this process has also a fact of increasing interest in the utilization of obtained data from these systems. It was noticed, that obtained information from this data could be very important source of knowledge about the process carried out, and about exploitation of monitored devices (Brodny et al., 2016b; Stecuła et al., 2018; Zhang et al., 2014). Currently, data collected by these systems illustrate course of monitored process are almost exclusively used for the real-time visualization and reporting of individual parameters.

However, more often a need for wider application of acquired data resources is increasingly recognized. Particularly, this applies to possibility of their application to identify and define more advanced diagnostic models of monitored machines and devices. In the case of the mining industry, this refers to e.g. full cycle of work and maintenance of these machines. One of the acknowledged methods of identification of such models is the approach by analyzing data obtained during the operation of machine or device. On the basis of such assumption, an attempt was made to develop a methodology using recorded data to diagnose the state of machines' operation and to develop the basis for potential forecasting of this state.

Researches in this area were focused on the machines that are part of mechanized longwall complex. It was assumed, that these machines are the most important link in the whole mining operation process. However, due to the availability of data and their size, in this paper only results of analyzes of longwall shearer were presented. Shearer is the most important machine of this complex, which directly mines of the rock mass. In the paper there are presented concepts of the application of data obtained from industrial automation system to analyze effectiveness of shearer's operation and to diagnose its technical condition. It should be also emphasized, that in presented results only the part of registered by these systems were used. The aim of this paper was to aware users of machines and encourage them to wider practical use of capabilities of industrial automation systems. It should improve the efficiency and safety of the mining production process.

\section{CHARACTERISTICS OF INVESTIGATED TECHNICAL SYSTEM}

Longwall shearer was the machine used for the studies (Fig. 1). It has complex technical structure and consists of mechanical, hydraulic and electrical systems, which are integrated to form a technical system, for which the whole shearer is being considered. Most of these systems are independent, and the structure of their cooperation from the reliability point of 
view is serial. Shearer has number of assemblies and subassemblies, that create a kind of mega-machine. Therefore, connection of the series of mechanical systems with the electrical and electronic systems makes it a complicated mechatronic system. Effectiveness of the entire mining exploitation process depends on the shearer's efficiency. Due to that, it is very important to monitor the parameters of its operation. Due to the fact, that shearer works in conditions that are not entirely definable, these data can be also a source of information about these conditions.

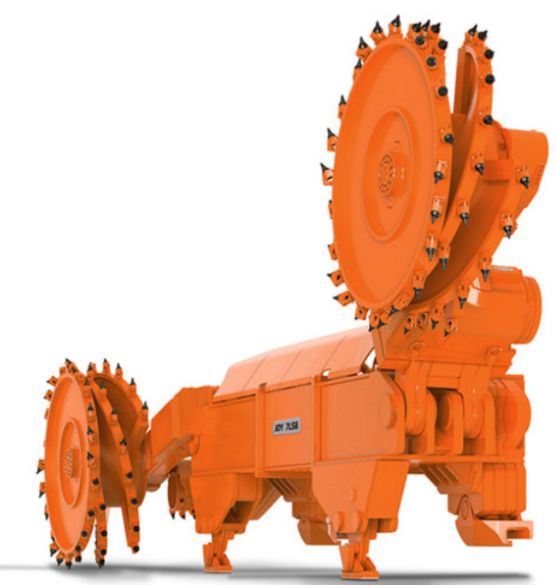

Source: (Mining Komatsu, 2018).

Fig. 1. Longwall shearer

Longwall shearer is equipped with the complicated modern systems of control, registration, as well as transmission of data about its operational parameters. Devices that create this technology must fulfill the explosion- and flame-proof high requirements. Example of such device applied in the shearer is Mincos controller, made by Becker Warkop company, presented in Figure 2 (Becker-Mining, 2018).

Whereas, in Figure 3 there is presented view of the control panel of shearer's hydraulic pump, and in Figure 4 controller's communication block for transmission of data from the shearer.

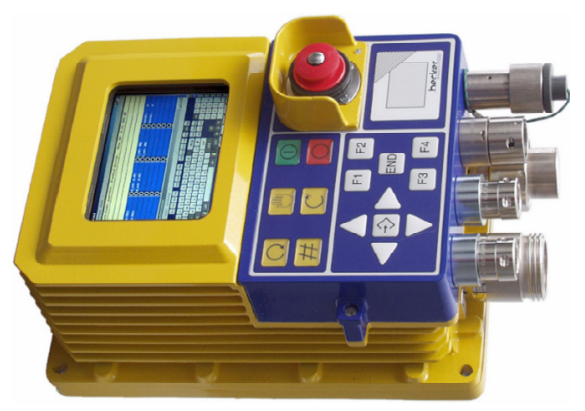

Fig. 2. View of the Mincos controller, made by Becker Warkop company Source: (Becker-Mining; 2018).

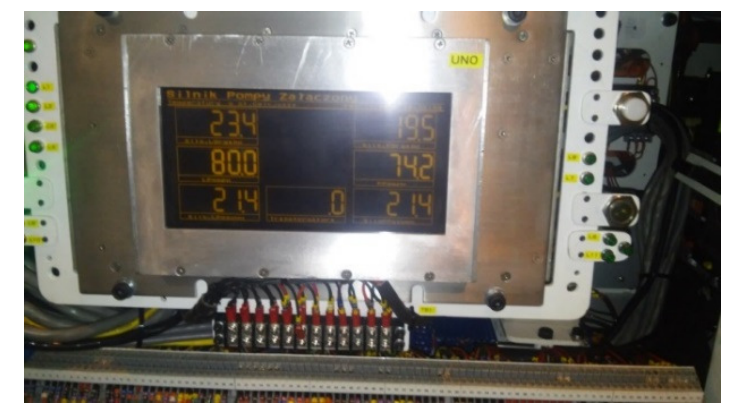

Fig. 3. View of the control panel of shearer's hydraulic pump 


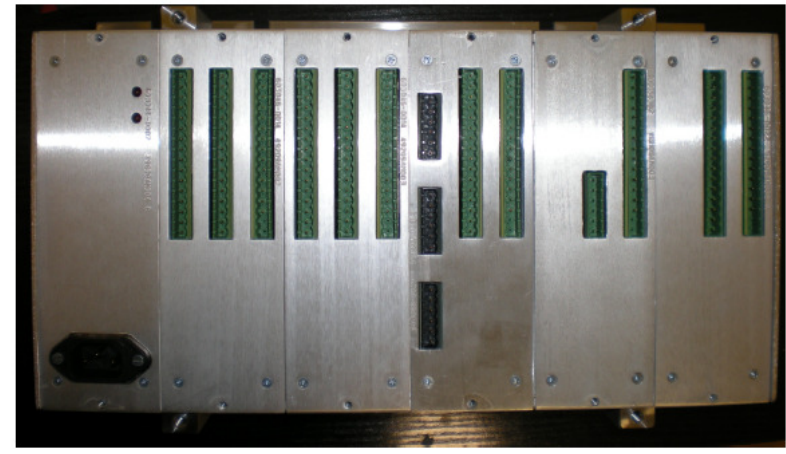

Fig. 4. View of the controller's communication block for transmission of data from the shearer

Presented devices, together with the number of other equipment, create the system for registration, archiving and partial transmission of data on operational parameters of shearer. Application of these devices causes that in currently used shearers, number of registered data is very large and includes number of operational parameters including also emergency states. This enables current assessment of shearer state and more advanced analyzes related to the external conditions in which the exploitation is carried out.

\section{RESEARCH RESULTS}

As already mentioned, automatic system in the shearer registers series of parameters of its operation. Amount of collected data is very large, and in most of cases it is used only for the current assessment of its operation status, as well as the status of individual components. In presented paper, possibilities of use of this data to analyze the availability of the shearer and to examine change in value of other operational parameters.

Regarding the studies of shearer's availability, there was determined its working time with respect to the total (normative) working time, during which it should work. This time was also determined with respect to the time of full technological cycle. That cycle determines the total time in which the shearer completes one full run over the mined longwall. It includes maneuvering movement (phase 1), slotting (phase 2) and mining process itself (phase 3). In the investigated case the unidirectional mining was analyzed. Time course of shearer's position in the longwall and the current intensities of its mining engine and hydraulic pump, are shown in Figure 5.

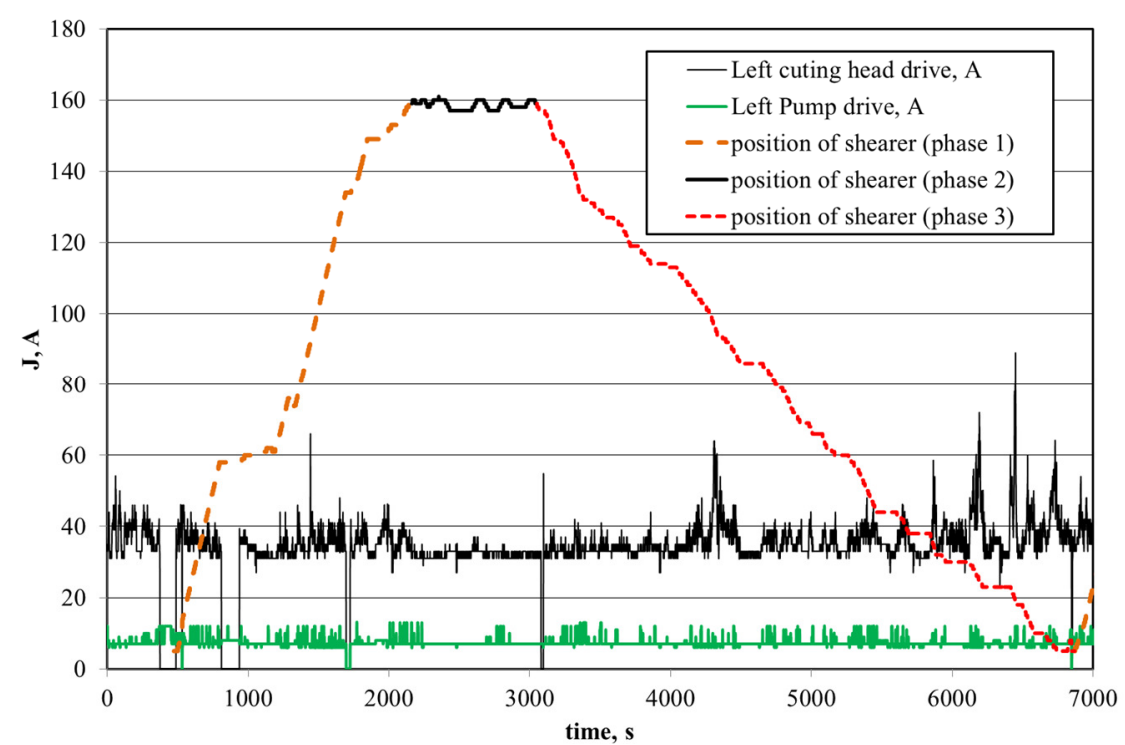

Fig. 5. Time course of shearer's position in the longwall and the current intensities of its mining engine and hydraulic pump 
Presented course relates to one work cycle of shearer. It includes about 109 minutes. For this period the availability index was determined, which also was related to shearer's particular work phases. The summary of results of shearer's availability analysis for this cycle is shown in Table 1. Moreover, in table there are shown times of unplanned stops for particular phases and for the entire cycle.

\section{Table 1}

The summary of results of shearer's availability analysis for cycle

\begin{tabular}{|l|c|c|c|c|}
\hline & Phase 1 & Phase 2 & Phase 3 & Whole cycle \\
\hline Work time, s & 1697 & 889 & 3754 & 6340 \\
\hline Times of unplanned stops, s & 574 & 546 & 1765 & 2885 \\
\hline Availability indicator, \% & $66.2 \%$ & $38.6 \%$ & $52.9 \%$ & $54.5 \%$ \\
\hline
\end{tabular}

Analysis of obtained results allows to evaluate particular shearer's operation phases in given mining cycle. Such partial analysis allows to precisely identify problems occurring during production process. Obtained index values show, that in the presented case, the highest time losses occurred in the slotting phase. It is significant information for the traffic maintenance staff, that this phase should receive more attention and cause of such state should be determined.

Data registered by the industrial automation system allows to rate also other shearer work parameters.

In Figure 6, there is presented time courses of temperature changes in different shearer subsystems for slotting (phase 2) and mining phases (phase 3).

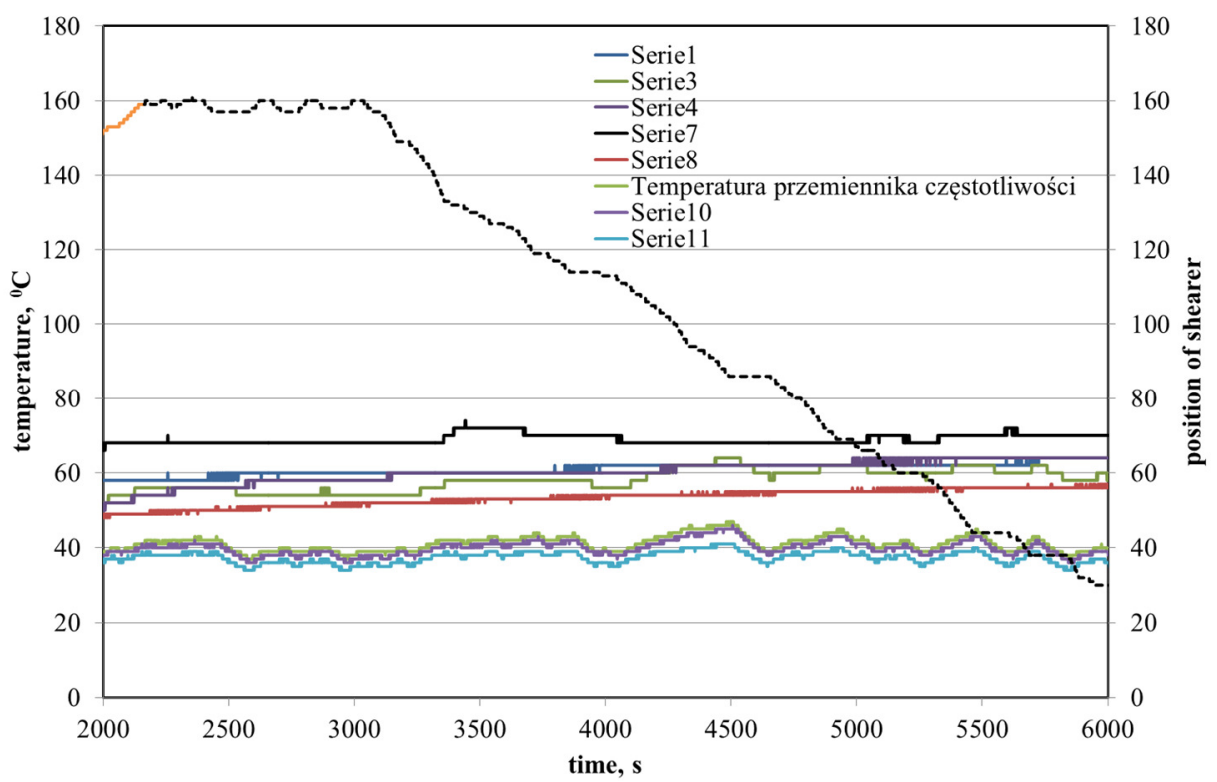

Fig. 6. Time courses of temperature changes in different shearer subsystems for slotting and mining phases

Presented courses allow for precise analysis of particular shearer subsystems' state. Based on that it is possible to determine the symptoms of machine failure or overloading. In the analyzed case, none of such phenomenon were observed.

\section{CONCLUSION}

Growing competition on the energetic market makes the mining enterprises optimize their production. One of such areas is traffic maintenance, associated with effective usage of technical assets of such enterprises. For such purposes, more widely applied industrial 
automation systems should be used. Those systems are applied in most of currently produced machines. It creates the possibility to fully monitor and diagnose parameters of such machines during the work periods. It is especially important in the mining industry, because of very difficult, changing and unpredictable operation conditions of such machines. Gathered data about their operational parameters allow to analyze their application level and operational condition, practically in any moment of usage.

Exploitation of machines in difficult mining conditions may cause different type of failures and damages. However, most of incidents of this type may be foreseen based on e.g. changes of temperature of particular subsystems. This allows to take precautionary actions and to avoid costly downtime and repairs. Observation of machine's operational parameters also allows to evaluate the conditions in which the machines work. It is particularly important in a case of shearer. Because properties of exploited formation are not completely known. During the exploitation many factors, that would disturb this process, can occur. Due to that, monitoring of such parameters should limit such events, and foremost, minimalize their consequences.

Analysis presented in the paper clearly shows, that industrial automation systems can significantly influence on the improvement of machines exploitation. For investigated shearer, a very detailed analysis of its work can be made, e.g. with respect to its particular work phases. Without automatic registration of data, such analysis cannot be made. Moreover, presented temperature change courses of particular subsystems of the shearer allow to determine their load. This in turn, allows to correctly maintain the exploitation process.

It can be assumed, that industrial automation systems for the ability to acquire reliable data concerning the machines' operational parameters allow for effective and safe mining exploitation. At the same time, in areas such as mining, they should be used in greater degree, in order to improve the efficiency of whole mining production process.

\section{ACKNOWLEDGEMENTS}

This article is the result of the research project No. PBS3/B6/25/2015 „Application of the Overall Equipment Effectiveness method to improve the effectiveness of the mechanized longwall systems work in the coal exploitation process" realized in 2015-2018, financed by NCBiR.

\section{REFERENCES}

Bolton W. (2007). Bausteine mechatronischer Systeme, Pearson, 20062. Bernstein H., Mechatronik in der Praxis, VDE.

Brodny J., Tutak M. (2016a). Determination of the zone endangered by methane explosion in goaf with caving of operating longwalls. SGEM2016 Conference Proceedings, Book1 Vol. 2, 299-306 pp. DOI: 10.5593/SGEM2016/B12/S03.039.

Brodny J., Stecula K., Tutak M. (2016b). Application of the TPM strategy to analyze the effec-tiveness of using a set of mining machines. SGEM2016 Conference Proceedings, Book1 Vol. 2, 65-72 pp. DOI: 10.5593/SGEM2016/B12/S03.009.

Palka D., Brodny J. Stecula K. (2017). Modern means of production and the staff awareness of the technical in the plant of the mining industry. CBU International Conference Proceedings 2017: Innovations in Science and Education, Vol. 5, Prague 2017, p. 1190-1194. DOI: 10.12955/cbup.v5.1094.

Feng-Li Lian, Moyne J., Tilbury D. (2002). Network Design Consideration for Distributed Control Systems, „IEEE Transactions on Control Systems Technology” Vol. 10, No. 2, 297-307.

Hedman, R., Subramaniyan, M., Almström, P. (2016). Analysis of critical factors for automatic measurement of OEE. Procedia CIRP 57, 128-133.

Jonsson, P., Lesshamar, M. (1999). Evaluation and improvement of manufacturing performance measurement systems - the role of OEE. Int. J. Oper. Prod. Manage. 19(1), 55-78.

Kwiecień R. (2012). Komputerowe systemy automatyki przemysłowej. Helion, Gliwice.

Miu D. K. (1993). Mechatronics - electromechanics and contromechanics. Springer-Verlag, New York.

Palka D. (2017). The role and importance of training for improving the safety and awareness of the technical staff in the mining plant. CBU International Conference Proceedings 2017: Innovations in Science and Education, Vol. 5, Prague 2017, p. 1195-1198. DOI: 10.12955/cbup.v5.1095.

Stecuła K., Brodny J., Tutak M. (2018). Use of intelligent informatics module for registration and assessment of causes of breaks in selected mining machines. Intelligent Systems in Production 
Engineering and Maintenance ISPEM 2017, Advances in Intelligent Systems and Computing 637, pp.74-84.DOI 10.1007/978-3-319-64465-3 8.

Singh R.K., Clements E.J., Sonwaney E. (2018). Measurement of overall equipment effectiveness to improve operational efficiency. International Journal of Process Management and Benchmarking. Volume 8, Issue 2, doi.org/10.1504/IJPMB.2018.090798

Tutak M., Brodny J. (2017a). Analysis of Influence of Goaf Sealing from Tailgate On the Me-thane Concentration at the Outlet from the Longwall. IOP Conf. Series: Earth and Envi-ronmental Science 95, 042025 doi :10.1088/1755-1315/95/4/042025.

Tutak M., Brodny J. (2017b). Determination of Particular Endogenous Fires Hazard Zones in Goaf with Caving of Longwall. IOP Conf. Series: Earth and Environmental Science 95, 042026 doi:10.1088/1755-1315/95/4/042026.

Tutak M., Brodny J. (2017c). Degree of use of alternative sources for energy production for the economical aims in EU countries. SGEM2017 Vienna GREEN Conference Proceedings, 2017, Vol. 17, Issue 43, 635-642 pp; DOI: 10.5593/sgem2017H/43/S29.080.

Tutak M. (2017). Analysis of varying levels of methane emissions from coal mines in Poland. SGEM2017 Vienna GREEN Conference Proceedings, Vol. 17, Issue 43, 301-308 pp; DOI: 10.5593/sgem2017H/43/S19.038.

Uhl T. (2008). Projektowanie mechatroniczne - zagadnienia wybrane, Wydawnictwo AGH.

Zhang Y., Yang W., Han D., Kim Y. (2014). An Integrated Environment Monitoring System for Underground Coal Mines-Wireless Sensor Network Subsystem with Multi-Parameter Monitoring. Sensors 2014, 14, 13149-13170; doi:10.3390/s140713149.

http://www.becker-mining.com.pl/mincos_mmc.html [Accessed 17 Juny 2018].

https://mining.komatsu/pl/product-details/kombajny-\%C5\%9Bcianowe-marki-joy [Accessed 17 Juny 2018]. 